\title{
Comprehensive Evaluation of Urban Ecological Environment Quality Based on Entropy and Catastrophe Progression Methods
}

\author{
Hong Li and Yingchao Yuan ${ }^{\text {a, * }}$ \\ School of Management, Tianjin University of Technology, Tianjin 300384, China \\ a1154279979@qq.com \\ Corresponding author: Yingchao Yuan
}

\begin{abstract}
Keywords: Ecological Environment Quality; Entropy and Catastrophe Progression Methods; Comprehensive Evaluation.
\end{abstract}

\begin{abstract}
The Comprehensive evaluation of ecological environment quality is an important index to express the ecological environment quality and service function. Using the catastrophe progression method to analyze the comprehensive level of ecological environment system in the Yangtze River Delta area in 2008-2014 is our first task, then we study and assess the dynamic trend between the sevel years. The results show that: the overall level of ecological environment in the Yangtze River Delta region is low, but has a steady growth trend.
\end{abstract}

\section{Introduction}

According to the characteristics of ecological environment in the Yangtze River Delta area,we select the evaluation index and some mathematical methods to evaluate the ecological environment quality status, to ascertain different evaluation units, the existing problems and put forward countermeasures of comprehensive governance. Objective to evaluate the quality of ecological environment of the region, not only can provide scientific basis for environmental management and decision-making at all levels of government departments, but also has important practical significance to the sustainable development of regional strategic decision making[1].In the aspect of evaluation method is the most commonly used AHP and fuzzy comprehensive evaluation method.Although these methods have their own advantages, they all belong to the subjective evaluation methods, which affects the objectivity of the research results[2][3].The ecological environment system of Yangtze River Delta is the object of this paper. On the basis of city ecology theory, using entropy and catastrophe progression methods, we make a quantitative study on the comprehensive level of the ecological environment system in the Yangtze River Delta region, and analyze the operation status and development of the Yangtze River delta.

\section{Research design}

\subsection{Research method}

In this paper, the entropy catastrophe series method is used to calculate the level of ecological environment in the Yangtze River delta.

Catastrophe theory is a tool to describe the discontinuous phenomena in nature and social activities. It is used to recognize and predict the qualitative change of the process of discontinuity in nature and social phenomenon [4]. There are three kinds of common catastrophe models: cusp catastrophe, swallowtail catastrophe and butterfly catastrophe, as shown in table 1.

The potential function of the catastrophe model for each derivative, and make it zero, simultaneous equations to obtain the bifurcation set, you can get a Normalized formula, as shown in Table 1. The Normalized formula can be calculated the comprehensive index system of ecological environment system score, the same level of the index of "complementary" to take the average value, "non complementary" to "the minimax principle", finally calculates the comprehensive level of regional ecological environment. 
Table 1. Three Catastrophe models

\begin{tabular}{|c|c|c|c|c|}
\hline Catastrophe models & Potential function & $\begin{array}{c}\text { Control } \\
\text { variable }\end{array}$ & $\begin{array}{c}\text { Bifurcat-ion } \\
\text { set }\end{array}$ & $\begin{array}{c}\text { Normalized } \\
\text { formula }\end{array}$ \\
\hline Cusp catastrophe & $f(x)=x^{4}+a x^{2}+b x$ & $\begin{array}{l}a \\
b\end{array}$ & $\begin{array}{l}a=-6 x^{2} \\
b=8 x^{3}\end{array}$ & $\begin{aligned} x_{a} & =\sqrt{a} \\
x_{b} & =\sqrt[3]{b}\end{aligned}$ \\
\hline $\begin{array}{l}\text { Swallowtail } \\
\text { catastrophe }\end{array}$ & $f(x)=x^{5}+a x^{3}+b x^{2}+c x$ & $\begin{array}{l}a \\
b \\
c\end{array}$ & $\begin{array}{l}a=-6 x^{2} \\
b=8 x^{3} \\
c=-3 x^{4}\end{array}$ & $\begin{aligned} x_{a} & =\sqrt{a} \\
x_{b} & =\sqrt[3]{b} \\
x_{c} & =\sqrt[4]{c}\end{aligned}$ \\
\hline Butterfly catastrophe & $f(x)=x^{6}+a x^{4}+b x^{3}+c x^{2}+d x$ & $\begin{array}{l}a \\
b \\
c \\
d\end{array}$ & $\begin{aligned} a & =-10 x^{2} \\
b & =20 x^{3} \\
c & =-15 x^{4} \\
d & =4 x^{5}\end{aligned}$ & $\begin{aligned} x_{a} & =\sqrt{a} \\
x_{b} & =\sqrt[3]{b} \\
x_{c} & =\sqrt[4]{c} \\
x_{d} & =\sqrt[5]{d}\end{aligned}$ \\
\hline
\end{tabular}

The value of each control variable is in the range of $[0,1]$ by using catastrophe progression method, and the bigger the better. Therefore, the variable transformation method is used to process the control variables

\subsection{Index design and data sources}

In this paper, the comprehensive level of ecological environment system is measured from three aspects: the intensity of ecological environment pollution, the intensity of ecological environment governance and the intensity of ecological environment construction.

The index of ecological environmental pollution intensity indicates the pressure of human economic and social activities on the environment. The intensity of the ecological environment governance indicates the measures taken by the human being to the ecological environment of the decline of carrying capacity. The intensity of ecological environment construction is the basic embodiment of human survival and reproduction. Specific indicators are shown in table 2.

Table 2. Index system

\begin{tabular}{|c|c|c|c|c|}
\hline System & Criterion layer & Index layer & Nature & Weight \\
\hline \multirow{9}{*}{$\begin{array}{l}\text { Ecological } \\
\text { environment } \\
\text { (G) }\end{array}$} & \multirow{3}{*}{$\begin{array}{l}\text { the intensity of } \\
\text { ecological } \\
\text { environment } \\
\text { pollution } \\
\text { (G1:0.2048) }\end{array}$} & Industrial wastewater discharge(Million tons) (G11) & - & 0.5515 \\
\hline & & $\begin{array}{l}\text { Industrial exhaust emission(Billion cubic meters) } \\
\text { (G12) }\end{array}$ & - & 0.2212 \\
\hline & & Industrial solid waste production(Million tons) (G13) & - & 0.2273 \\
\hline & \multirow{3}{*}{$\begin{array}{l}\text { the intensity of } \\
\text { ecological } \\
\text { environment } \\
\text { governance } \\
\text { (G2:0.3502) }\end{array}$} & $\begin{array}{l}\text { Environmental governance investment accounted for } \\
\operatorname{GDP}(\%) \quad(\mathrm{G} 21)\end{array}$ & + & 0.4821 \\
\hline & & $\begin{array}{l}\text { Daily sewage treatment capacity(Million cubic } \\
\text { meters) (G22) }\end{array}$ & + & 0.3255 \\
\hline & & $\begin{array}{c}\text { Comprehensive utilization rate of industrial solid } \\
\text { waste }(\%) \quad(\mathrm{G} 23)\end{array}$ & + & 0.1924 \\
\hline & \multirow{3}{*}{$\begin{array}{l}\text { the intensity of } \\
\text { ecological } \\
\text { environment } \\
\text { construction } \\
\text { (G3:0.445) }\end{array}$} & Per capita park area(Square meters per person) (G31) & + & 0.3203 \\
\hline & & Built-up area green coverage rate $(\%) \quad(\mathrm{G} 32)$ & + & 0.4013 \\
\hline & & Forest coverage $(\%) \quad(\mathrm{G} 33)$ & + & 0.2784 \\
\hline
\end{tabular}

In this paper, the ecological environment evaluation index data is derived from "China Statistical Yearbook", Provincial Yearbook and National statistical data. 


\section{Empirical analysis}

\subsection{Comprehensive evaluation of ecological environment}

The method of range transformation is used to deal with the specific indexes. The nature of each evaluation index is shown in table 1.

Positive index, $y i j=\frac{x i j-x \min (j)}{x \max (j)-x \min (j)}$; Negative index, $y i j=\frac{x \max (j)-x i j}{x \max (j)-x \min (j)}$

2. Using entropy method to determine the importance of the same level index.

In information theory, entropy is a measure of the degree of disorder in the system. The entropy method is used to measure the weight of the same level index [5]. The results are shown in Table 2.

3. Using catastrophe progression method to calculate the score of each level.

Figure 1 is the urban ecological environment measurement model based on catastrophe progression method. $G=(\sqrt{G 3}+\sqrt[3]{G 2}+\sqrt[4]{G 1}) / 3$.

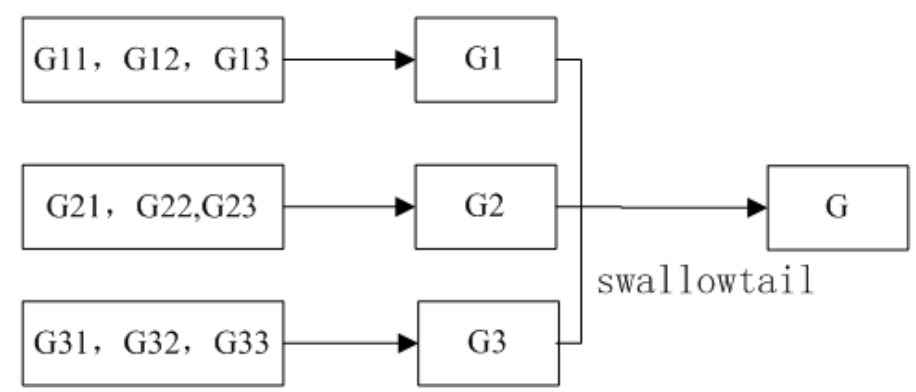

Fig. 1 Measurement model

\subsection{Analysis of comprehensive evaluation of ecological environment}

Through the above analysis, we can get the results of the comprehensive evaluation of ecological environment in the Yangtze River Delta and the evolution trend as shown in figure 2.

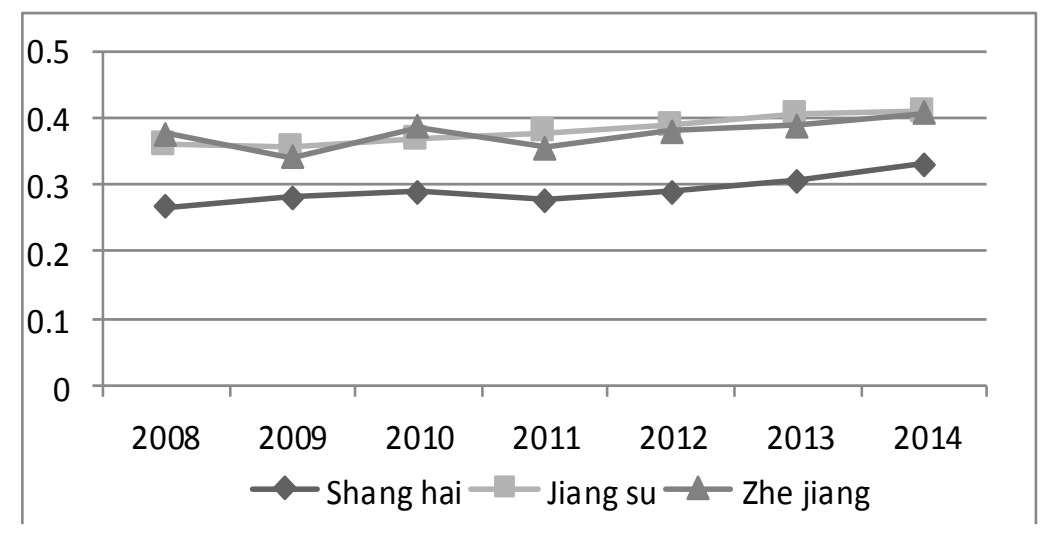

Fig. 2 Comprehensive evaluation of ecological environment

The above characteristics show that the comprehensive level of ecological environment in the Yangtze River Delta region is relatively low, in the vicinity of 0.35 , showing a slow upward trend year by year.

\section{Conclusion}

In this paper, the comprehensive evaluation index system of ecological environment system is constructed from 3 aspects: the intensity of ecological environment pollution, the intensity of ecological environment governance and the intensity of ecological environment construction. This paper makes an empirical study on the evolution of environmental carrying capacity in the Yangtze River delta based on the entropy catastrophe series model. The study found that the overall ecological environment of the Yangtze River Delta region is low, and has a steady growth trend. 


\section{References}

[1]. Suting Ma, Jie Tang, Nianfeng Lin. Comprehensive evaluation of ecological environment in Western Jilin based on GIS and RS[J]. Resource Science,2004,26(4):140-145.

[2]. Huiyong Wang, Yuliang Chen, Yongqin Rui. Comprehensive evaluation of pavement condition based on matter element model[J].Journal of traffic and Transportation Engineering,2004, 26(4):140-145.

[3]. Zhenyao Shen, Tongfang Xie, Tianwei Qian. Comparison of fuzzy comprehensive evaluation method, grey clustering method and meta-analysis method in environmental quality assessment[J]. Pollution control technology, 1997(2):72-74.

[4]. Linyu Xu, Peng Kang, Renzhi Liu. Dynamic evaluation method of environmental carrying capacity of Industrial Park Based on Catastrophe Theory[J]. China Environmental Science, 2013, 33(6):1127-1136.

[5]. Ruili Guo, Qinyu Zheng, Juan Liu, et al. Urban ecosystem health assessment based on entropy method and GM $(1,1)$ model in Chongqing[J].China Environmental Science,2012, 32(6): 1148-1152. 